\title{
A Social Solution to the Puzzle of Doxastic Responsibility: A Two-Dimensional Account of Responsibility for Belief
}

\author{
Robert Carry Osborne \\ (This is a final, pre-copyedit version of an article published in Synthese. The final authenticated version is available online \\ at: http://link.springer.com/article/10.1007/s11229-020-02637-9)
}

\section{Introduction}

There are various, well-known difficulties surrounding the notion of doxastic responsibility and the so-called 'ethics of belief'. The "puzzle of doxastic responsibility," as Miriam McCormick (2015) has recently called it, arises from the tension between some version of the following three claims, each intuitively plausible on its own, but together jointly inconsistent:

(RESPONSIBLE) We sometimes rightly hold agents responsible for their doxastic attitudes. (CONTROL) Voluntary control over $\mathrm{X}$ is a prerequisite for responsibility for $\mathrm{X}$.

(NON-VOLUNTARY) Beliefs are not subject to the will, that is, we lack voluntary control over them. ${ }^{1}$

The puzzle, then, is why beliefs seem to be the kinds of things for which we can rightly be held responsible, and yet do not appear to be something over which we exercise direct (voluntary or intentional) control. ${ }^{2}$ A solution to the puzzle seems to require that we reject at least one of the three claims above. As a result, the puzzle has three general answers: (a) Reject (RESPONSIBLE) and thus deny that beliefs are the proper objects of normative assessment, and so deny that anyone

\footnotetext{
${ }^{1}$ McHugh (2017) also discusses a version of the same puzzle, which he calls "the problem of epistemic responsibility," though his version involves four claims, and depends explicitly on a comparison with the kind of control we have over our (bodily) actions. This added comparative claim is helpful, since the puzzle arguably arises partly from thinking that responsibility for belief must share certain features of responsibility for action. However, I will not here discuss responsibility for action, and will focus on the simpler version of the puzzle.

2 The puzzle is often traced back to The Anti-Voluntarism Argument, usually attributed to William Alston (1989), but has been given in various forms. Sharon Ryan (2003) gives a version of the argument in terms of "epistemic obligations" requiring voluntary control, which is effectively Alston's original version. McCormick (2015) gives a modified version in terms of "attributions of responsibility for beliefs" instead of "epistemic obligations." I am interested here in the issue of responsibility for belief rather than the notion or possibility of epistemic obligations, so I will be concerned with McCormick's version of the argument. It is an open question, of course, whether the very notion of responsibility for belief requires the notion of epistemic or doxastic obligations.
} 
is really ever responsible for what they believe, ${ }^{3}$ (b) Reject (CONTROL) and argue that responsibility for belief does not require voluntary doxastic control, ${ }^{4}$ and (c) Reject (NoNVOLUNTARY) and argue that beliefs are subject to voluntary control, i.e., doxastic voluntarism. ${ }^{5}$

Answer (b) typically takes the form of arguing that we have some non-voluntary or nonintentional form of doxastic control sufficient to ground responsibility for belief. But answer (b) can also involve denying that doxastic control is required for doxastic responsibility, full stop. This potential solution to the puzzle faces significant resistance, since it is a common view that normative responsibility of any form has some kind of control condition. ${ }^{6}$ In this paper, I propose a version of the 'no control required' solution to the puzzle. I will argue that doxastic responsibility is not grounded in doxastic control, whether voluntary or non-voluntary.

One motivation for pursuing this 'no control' approach here is that the focus on the issue of doxastic control in the debate has led to a proliferation of different conceptions of 'control', yet few clear constraints on how that term should be used or applied. ${ }^{7}$ This of course does not on its own imply that the debate over doxastic control is merely verbal, or that distinctions between kinds of doxastic control fail to track real differences. Much more would need to be said to motivate

\footnotetext{
${ }^{3}$ See Levy $(2007,2011)$, and arguably also Alston (1988). McCormick (2015) argues that Hieronymi (2008) can and perhaps should be read as giving a version of this answer as well.

${ }^{4}$ See Feldman (2000, 2001), Heller (2000), Smith (2005, 2008), Chrisman (2008), Hieronymi (2006, 2008), Weatherson (2008), and McHugh (2017).

${ }^{5}$ See Ginet (2001), Ryan (2003), Steup (2000), and arguably McCormick (2011, 2015).

${ }^{6}$ However, some theorists have taken this route: Chuard \& Southwood (2009), Chrisman (2008), Feldman (2000, 2008), Kornblith (1983, 2001), and Owens (2000) all seem to go this way. Though one wrinkle here is that Chrisman, Feldman, and Kornblith are seeking to give accounts of epistemic obligations or doxastic oughts, and Chuard \& Southwood of epistemic norms and demands, where all of them seem to hold that the central lesson is about epistemic normativity generally. So none of their accounts are explicitly or specifically ones of doxastic responsibility. Of course, it is perhaps only a short step from obligations, oughts, and norms to responsibility - but it is one in need of substantial elucidation.

${ }^{7}$ E.g., see Boyle (2009) for intrinsic control, Smith (2005) for rational control, Hieronymi (2006, 2008) for evaluative control, Rettler (2018) for reflective control, McHugh (2017) for attitudinal control, McCormick $(2011,2015)$ for guidance control, Moran (2001) for deliberative control, and Peels (2017) for a rejection of doxastic control in general and an argument instead for doxastic influence. Meanwhile, Levy (2007) holds that dual control is required for doxastic responsibility, and so no non-voluntary or compatibilist form with suffice. Ryan (2003), Heller (2000), and Weatherson (2008) also discuss different forms of doxastic control, but don't name them. There is also disagreement in the literature about whether 'non-voluntary control' is conceptually possible. E.g., see McHugh (2017).
} 
those claims, and I won't pursue such arguments here. However, given that there are so many different conceptions, and little agreement about how to apply the central term, it seems worthwhile to see if we can make progress on doxastic responsibility while bracketing the issue of control. Another, perhaps more significant, motivation for my account here is the view that individualistic accounts that focus on control leave out the importantly social dimension of responsibility for belief.

The central contention of this paper, then, is that doxastic responsibility is not only responsibility for, but responsibility to: that is, part of being responsible for our beliefs is being responsible to others. In order to articulate this idea, I will argue that doxastic responsibility should be understood, most fundamentally, as a form of answerability, and that this gives us a way of addressing the puzzle above. My account will have two parts, corresponding to two dimensions of answerability that warrant explanation: an individual dimension and an interpersonal dimension. The individual dimension of answerability is a matter of being the intelligible subject of demands for reasons or justification for one's beliefs. ${ }^{8}$ We are responsible for our beliefs, in this first sense, in that we can be called to rationally "answer for" them. Some features of the individual dimension are, I will argue, explicable in terms of the nature of belief. In particular, the normativity of belief determines which kind of reasons-namely, evidential or truth-related ones - are relevant to answerability. I will suggest that the individual dimension of answerability does not require doxastic control, and so provides us with an initial way of rejecting (CONTROL) above.

However, I will contend that resolving the puzzle merely in terms of the individual dimension of answerability gives only an incomplete picture of doxastic responsibility; important questions remain unanswered. We also need an account of the interpersonal dimension of answerability. Namely, how and why does being responsible for our beliefs involve being

\footnotetext{
${ }^{8}$ See Smith (2015b) for a discussion of answerability in relation to the notion of 'intelligibility'.
} 
responsible to others? Why do we (generally speaking) owe it to others to engage in the social practice of answerability, and to make good faith efforts to justify our beliefs when appropriate? I will argue that understanding the essentially social features of doxastic responsibility requires an account of our social relations of dependence and the accompanying social expectations. It is, then, our dependence upon one another qua believers, and what we are entitled to expect of one another given this dependence, that completes the picture of what it is to be responsible for one's beliefs beyond merely the individual dimension of answerability. I will suggest that, like the individual dimension, the interpersonal dimension also does not require doxastic control. In conjunction with the individual dimension, then, my account of the interpersonal dimension of answerability aims to give us a decisive way of rejecting (CONTROL).

It is worth noting that the view that doxastic responsibility is a form of answerability, and that this can address worries about doxastic voluntarism, is not new. Pamela Hieronymi (2008) has argued for a well-known version of this view, and so it is worth saying something about how my view is indebted to and also differs from hers. ${ }^{9}$ Firstly, my account endorses Hieronymi's view that belief - as one of the "commitment-constituted attitudes" - comes along with its own form of answerability. I follow Hieronymi in holding that the kind of reasons that are relevant to answerability (for belief) are evidential or epistemic reasons. In this sense, my account of the individual dimension of answerability shares important features with Hieronymi's.

However, the view I articulate here departs from Hieronymi in various ways. First, while Hieronymi argues that what she calls "evaluative control" is required for doxastic responsibility, I prefer not to think in terms of the notion of control. ${ }^{10}$ Second, Hieronymi seems to hold that what one is ultimately responsible for is one's "epistemic personality" or "the quality of one's will," as

\footnotetext{
${ }^{9}$ Angela Smith (2005) has also argued for an answerability view of attitudinal responsibility. I will discuss aspects of Smith's view at greater length below.

${ }^{10}$ The degree to which this simply marks a terminological preference is a sticky issue. I'm inclined to think there is a substantial disagreement to be had here that goes beyond terminology. I will address this more below.
} 
reflected in one's beliefs, and that this responsibility is intimately tied to the reactive attitudes. While I think that both the reactive attitudes and the notion of an agent's "epistemic personality" are important in various ways, my view does not appeal to either of them. Lastly, and most importantly, my view ultimately gives a social explanation of how and why we are responsible for our beliefs, in the form of the interpersonal dimension of answerability, which departs in significant ways from Hieronymi’s account.

The paper will proceed as follows. In $§ 2$, I will make some preliminary remarks about the general issue of responsibility and its relation to the puzzle at issue. In $\S 3$, I develop the first part of my account, the individual dimension of answerability, certain features of which are explained by the normativity of belief. In $\S 4$, I develop the second part of my account, according to which answerability's status as a genuinely interpersonal form of responsibility depends on features of human sociality. In $§ 5$, I return briefly to Hieronymi’s view of doxastic responsibility, and discuss how my view differs from and is intended to go beyond hers. In $\S 6$, I consider and respond to three objections. And in $§ 7$, I conclude. ${ }^{11}$

\section{Some Preliminary Remarks about Responsibility and the Puzzle}

One might wonder right out of the gate why we should think that answerability is the model of responsibility relevant to doxastic responsibility. Indeed, there are various conceptions of responsibility available that might fill the role. The notions of attributability and accountability have also been taken to embody different senses or "faces" of responsibility. ${ }^{2}$ Along with answerability, they can be understood, in broad strokes, as follows:

\footnotetext{
${ }^{11}$ I'll note that the account I give in this paper is intended as an account of responsibility for belief in the sense of full belief, rather than partial belief or rational credence. It seems plausible that we are responsible for our partial beliefs and credences as well, and I suspect that my account could be extended, mutatis mutandis, to these attitudes as well. But I will not argue for that extension here.

${ }^{12}$ E.g., see Watson (1996) and Shoemaker (2011).
} 
Answerability: a matter of being the intelligible target of a demand for reasons or justification for an action or attitude, and associated responses such as rational criticism

Attributability: a matter of an action or attitude properly being an agent's own, e.g., being tied it to her agency such that she can be evaluated for it

Accountability: a matter of being subject to the normative expectations of others, or the demands of some prescriptive norm(s), often in second-personal manner, and associated responses such as the reactive attitudes

Given that it is perhaps more common to think of doxastic responsibility as a form of accountability - either in terms of being accountable to prescriptive epistemic norms ${ }^{13}$ or as being the proper target of the reactive attitudes ${ }^{14}$ — why should we think answerability is the primary notion here? One may object that answerability is merely a downstream effect of the actual phenomenon that is constitutive of responsibility, e.g., that one is accountable to prescriptive norms that govern the propriety of one's attitude. We can, the objection goes, have responsibility without answerability, and thus responsibility cannot simply be answerability.

While it is beyond the scope of this paper to offer anything like a full or decisive argument in response to this objection, I will offer a brief sketch of how I suggest we are to understand the relation between answerability and accountability. I suggest that accountability is parasitic on answerability in the following way: being appropriately (held) accountable to demands, norms, or expectations depends on one's basic status as answerable (in the individual dimension) for one's actions and attitudes. ${ }^{15}$ That is, being the intelligible subject of a demand for reasons is a precondition on being accountable to prescriptive demands or norms. If one were not answerable for one's attitudes and conduct, in the sense that one was not the intelligible subject of a demand for justification, then I think there would be no sense in which one could be (appropriately held) accountable to norms governing one's attitudes and conduct (though one could perhaps still be

\footnotetext{
${ }^{13}$ E.g., see McHugh (2013, 2017).

${ }^{14}$ E.g., see Hieronymi (2008), McCormick (2011, 2015), Peels (2017), and Tollefsen (2017).

${ }^{15}$ See Smith $(2012,2015 b)$ for arguments to this effect.
} 
evaluated relative to some standard). So, at least in this sense, I suggest that answerability is more basic than accountability, and so the former is not merely a downstream effect of the latter. There, of course, remains much more to be said here, and I will return to this issue towards the end of the paper. But for the purposes of the paper going forward, I will think of answerability as more fundamental than accountability for the above reasons.

\section{The Individual Dimension of Answerability: Intelligibility and Norms of Belief}

I want to begin by filling out the conception of doxastic responsibility as a form of answerability: to be responsible for one's beliefs is to be answerable for them. ${ }^{16}$ Answerability is associated with a set of normative demands: if one is answerable for an attitude, one can-in principle - be asked to "answer for" that attitude. The individual dimension of answerability concerns being the intelligible subject of a demand for reasons or justification, in the sense that it would in principle make sense to be asked to rationally defend or justify one's attitude. The demand for reasons here concerns the reasons on which one's belief is based: the reasons that one takes to justify or rationalize the holding of the belief. That is, not merely reasons that could justify the belief, but one's own reasons for the belief. ${ }^{17}$ This is distinct from a mere inquiry into one's reasons in that that could simply be a search for an explanation for one's belief, rather than a justification of it. In the case of belief, the demands of answerability embody an epistemic standard: that is, the associated demand for reasons is a demand for reasons that show that the belief is (likely to be) true. ${ }^{18}$

\footnotetext{
${ }^{16}$ I take this claim to apply to doxastic attitudes generally, not only beliefs. So one is answerable for one's beliefs, one's states of disbelief, and one's suspensions of belief or judgment. It may also be that one can be answerable for absences of doxastic attitudes, e.g., where one in a sense should believe something that one has no attitude about. For the most part, I will speak in terms of 'belief', but I mean this to apply to the doxastic attitudes in general.

${ }^{17}$ In this sense, the demand for reasons concerns doxastic justification and not merely propositional justification.

${ }^{18}$ As Hieronymi (2008: 365) argues, "believing brings with it its own distinctive form of answerability. In believing, you are answerable for reasons that you take to show the belief true."
} 
This feature of doxastic answerability, that the reasons relevant to a demand for justification are epistemic reasons, is explicable in terms of the normativity of belief. Normativism about belief (hereafter simply 'normativism') is, broadly, the view that certain standards or norms - typically epistemic norms or norms of rationality — are intrinsic to or 'built into' the nature of belief. ${ }^{19}$ The most common forms of normativism hold that belief is subject to a truth norm, a knowledge norm, or a norm of justification. ${ }^{20}$ Normativism is typically employed in order to explain the source and structure of epistemic normativity, or some features thereof.

The idea that there is a norm of belief is sometimes thought to fall out of the idea that there is an aim of belief, where the aim provides or constrains the norm. ${ }^{21}$ While I won't be mounting a sustained defense of normativism or a belief-aim here (many others have done so), a fairly common way to defend the view is to note that the attitude of belief seem to constitutively involve a commitment to the truth of a proposition. That is, to believe that $p$ is to take $p$ to (actually, not imaginatively) be the case. Deliberation about what to believe is thus sometimes said to be 'transparent' to the question of what is the case: the question of whether to believe $p$ simply collapses to the question 'whether $p .{ }^{22}$ So, belief seems to be intrinsically regulated by considerations bearing on truth. In this sense, belief can be said to "aim at truth." Different conclusions might be drawn from this. One might conclude that belief is subject to a standard of correctness, such that a false belief is defective, i.e., incorrect. ${ }^{23}$ Similarly, one might conclude that belief is uniquely rationalized by truth-related reasons, since questions about what to believe

\footnotetext{
${ }^{19}$ See Nolfi (2015) for a recent discussion and defense of normativism. See also McHugh \& Whiting (2014) for a general discussion of the view.

${ }^{20}$ For example, Wedgwood (2002) holds that the aim of belief is truth, which in turn gives rise to a standard of correctness and a norm of rationality for the practice of reasoning. Hieronymi $(2006,2008)$ holds that belief is subject to a truth norm in the sense that the kinds of reasons that uniquely rationalize belief are "constitutive reasons," that is, ones that bear on the truth of the belief's content.

${ }^{21}$ See Williams (1973) for an influential early version of the claim that belief aims at truth. See also Whiting (2012) on the idea that belief aims at truth. See McHugh (2011) for a defense of the claim that belief aims at knowledge, not merely truth. See also Wedgwood (2002).

${ }^{22}$ See Shah and Velleman (2005) for a discussion of 'transparency' in doxastic deliberation.

${ }^{23}$ E.g., see Shah and Velleman (2005).
} 
can only be answered by appeal to such reasons. ${ }^{24}$ Either way, the relevant upshot is that considerations of truth normatively govern belief in some fundamental way.

The demands of answerability are, I suggest, responsive to the normative centrality of truth for belief. This is compatible with a simple truth norm, a knowledge norm, or a justification norm that focuses on truth-related reasons. I will remain neutral on which of these is doing the relevant normative work, since it is beyond the scope of this paper to argue for one in particular. What is important, though, is that the demands of answerability, as applied to belief, are demands for justification in terms of reasons that act as evidence for a given belief: that is, reasons that show the belief is (likely to be) true. ${ }^{25}$

We next need to better understand the fundamental conditions in virtue of which agents are subject to the individual dimension of answerability. In order for agents to be answerable for their beliefs, those beliefs must be attributable to them: they must 'belong' to the agents in a way that makes them intelligible as things to demand reasons for. However, not everything that is attributable to us are things for which we are answerable. Thus, answerability requires a kind of rational attributability. Doxastic attributability is sometimes understood in terms of mechanism ownership: a doxastic attitude is attributable to an agent just in case she has taken ownership of the mechanism that produced that attitude, or that mechanism is properly 'hers' ${ }^{26}$

Alternatively, one might think that a belief is properly attributable to an agent when it reflects and is sensitive to her evaluative dispositions and judgments, such as those about her reasons. I propose to go with this latter option, and adopt something like Angela Smith's (2005,

\footnotetext{
${ }^{24}$ E.g., see Hieronymi $(2005,2006)$.

${ }^{25}$ This is very close to Hieronymi's $(2006,2008)$ view, although she does not put it in terms of a 'norm of belief' or in terms of answerability being partly grounded in such a norm. Rather, she argues that truth-related reasons are "constitutive reasons" for belief, while non-truth-related ones are "extrinsic reasons."

${ }^{26}$ E.g., see McHugh $(2013,2017)$ and McCormick $(2011,2015)$. Some reasons-responsiveness or guidance control views regard mechanism ownership as a necessary condition on doxastic responsibility and/or doxastic control. In Osborne (2019), I argue that there are important problems with McCormick's (2015) account of ownership.
} 
2015a, 2015b) view about what is required for answerability. She argues that an agent is answerable for an attitude when it reflects and is sensitive to her judgments, assessments of reasons, or dispositions to engage in judgments or assessments. Smith often calls this condition the judgment-sensitivity of attitudes (following T. M. Scanlon).

The notion that judgment-sensitivity is required for answerability gives us something to say about cases where, e.g., an agent has beliefs induced by posthypnotic suggestion, or is slipped some "belief pills" that suddenly give her a bunch of new beliefs. ${ }^{27}$ In such cases, it seems plausible to think that agents not answerable for those beliefs. This, intuitively, is because such "implanted" beliefs wouldn't reflect the agent's judgments and evaluative dispositions. Smith (2005: 262) holds that implanted attitudes are "not really the agent's own" if they are induced in ways that "bypass her rational capacities altogether." However, I think not all cases of implanted attitudes will be ones in which the attitudes fail to be the "agent's own," even if they bypass her rational faculties initially. It remains possible that an agent could have a belief "implanted" and have it connected up with her evaluative judgments or dispositions such that it would tell us about them. For example, imagine a case where an agent loses a host of beliefs due to brain damage, and the beliefs are then replaced via an advanced neural computer program, and the agent comes to hold them as she did before. $^{28}$

So, I suggest that what we need for answerability is not merely judgment-sensitivity, but rather something like the following:

Rational Situatedness Condition (RSC): An agent A is answerable (in the individual dimension) for a belief B iff (1) she holds B, and (2) B is rationally situated in her psychology such that it is linked to evaluative judgments, assessments, or dispositions towards activities like reasoning that themselves have not been implanted in ways that bypass or usurp her rational capacities.

${ }^{27}$ Smith (2005) discusses this general class of cases and calls them "implantation cases."

${ }^{28}$ See my discussion of this kind of case in Osborne (2019) for further details. 
This condition is rather similar to Smith's (2005) own Rational Relations View, according to which an attitude must stand in various "rational relations" with other parts of an agent's psychologyprincipally, her evaluative judgments — for her to be answerable for it. However, $R S C$ is different in that it allows that agents might come to hold attitudes in ways that (at least initially) bypass their rational capacities and still remain answerable for them. So, what matters for answerability is not that a belief is judgment-sensitive and non-implanted, but that it is connected to evaluative judgments, assessments, and dispositions towards reasoning in ways that represent the "normal" (i.e., non-manipulated) operation of one's rational capacities. One might be answerable, for example, for a belief one comes to hold on the basis of political propaganda that initially bypasses one's rational capacities as long as that belief reflects one's evaluative judgments and rational dispositions.

One might object, however, that $R S C$ simply reintroduces a control condition under a different name. Indeed, Smith (2005) herself suggests that the judgment-sensitivity of one's attitudes grounds what she calls rational control. But by this, she simply means that one can, in principle, alter one's attitudes through the activities of evaluative assessment and judgment. This is similar to Hieronymi's $(2006,2008)$ conception of evaluative control. But (at least for Smith) this is just to say that, when things go as they should, our doxastic attitudes are dispositionally responsive to our judgments. But even when they are not properly rationally responsive in this way, we can nevertheless still satisfy $R S C$, and thus be answerable for them. Presumably one form of epistemic irrationality is when our judgments about our evidence whether $p$ and our beliefs about $p$ are not in line. So we might fail to change our beliefs, even systematically, in response to good evidence because we are being irrational. But presumably we are typically still answerable for our beliefs even when they (or we) are irrational. $R S C$ does not require that we be able to 
change our beliefs in order to be answerable for them, and thus does not reintroduce the notion of 'control.'

If satisfying $R S C$ is sufficient for answerability, and does not require doxastic control, then it seems we've identified a strategy for solving the puzzle that the paper began with by rejecting (CONTROL). However, I want to argue next that if understanding doxastic responsibility in terms of answerability is to allow for a satisfying solution to the puzzle, more needs to be said. In particular, a complete understanding of doxastic responsibility as answerability requires a further account of the interpersonal dimension of answerability.

\section{The Interpersonal Dimension of Answerability}

\subsection{Why Do We Need to Go Beyond the Individual Dimension?}

One might wonder why we need a second part of the account that goes beyond the individual dimension of answerability. To see why, first note that the account of answerability given so far is essentially individualistic. While answerability can involve actual interpersonal exchanges of reasons, the individual dimension of answerability is just a matter of what makes an individual agent the intelligible subject of a demand for reasons. The individual dimension thus does not concern the issue of whether any actual demands are made or should be met. This is true, I think, of both Hieroynmi's (2008) and Smith's $(2005,2015 b)$ views. ${ }^{29}$ But because of this, the individual dimension doesn't tell us two important and related things: first, why, in being responsible for our beliefs, there is a sense in which we are responsible to others; and second, why some actual demands for reasons or justification have normative force such that we (generally

\footnotetext{
${ }^{29}$ Smith (2015: 103) makes essentially this point about answerability with respect to moral responsibility. She argues only that it must be "intelligible" to ask an agent to "answer for" her action or attitude, but allows that "there may not in fact be anyone in a position to legitimately make such a request of the agent in the circumstances."
} 
speaking) owe it to others to engage in good faith in the general social practice of giving and exchanging reasons.

Why think that the individual dimension of answerability can't provide answers to these questions? Well, it's not clear, even if I am answerable in the individual dimension, why I might owe it to you to actually provide my reasons if you demand them. Why should it matter to you what I believe, and what my reasons are? One might respond here that if there is a norm (of belief) that ought to be followed, then anyone can hold others responsible for (not) following it. However, this isn't obvious; not all norms are like this. For example, whether an agent follows norms of prudence is plausibly no one else's business, even if the agent is being irrational in not doing so. A reasonable response to someone's criticism that one is being imprudent is "You worry about you, and I'll worry about me." The reason moral norms seem to have this feature (that anyone can hold anyone to them) is, presumably, because they typically bear on how we ought to treat one another, and so already have a social dimension built in. ${ }^{30}$

So, without a consideration of the social features and norms of the interpersonal dimension of answerability, it's hard to see why actual demands for reasons for belief sometimes have interpersonal normative force. And yet, it seems that sometimes we do effectively owe it to one another to provide our reasons. This, then, is why the second part of the account is required: we need it to make sense of why we are entitled to expect others to participate in good faith in the shared practice of giving and exchanging reasons; to understand why we are not only the intelligible subjects of demands for reasons, but why we sometimes owe it to one another to do our best to fulfill those demands when we are subject to particular instances of them.

\footnotetext{
${ }^{30}$ It's unclear whether this explanation can also work in the case of moral duties to oneself. There is a question here about what separate moral duties to oneself from norms of prudence. I'll simply need to bracket this issue here.
} 
One might object, however, that the individual dimension of answerability does not in fact seem especially individual, since the very notion of making and being subject to demands itself seems interpersonal. Further, the individual dimension, as I've characterized it, concerns whether and which demands "make sense" to make of someone, which also seems like an interpersonal matter. So one might wonder what the real distinction between the two dimensions of answerability is, and why it should be understood in terms of an 'individual/interpersonal' divide.

This is a fair objection, and I'm inclined to agree that answerability itself has a naturally interpersonal flavor. However, I suggest that the individual dimension is "individualistic" in at least the following sense: we can ask whether an agent is answerable for a belief (in the individual dimension) by asking whether the impersonal demands of a norm, rather than those of an agent, are intelligible or rationally apt. These demands might be embodied in the demands of a particular agent who employs the norm, as they often are in a demand for reasons or justification. But in principle, we can ask whether an agent is answerable to the demands of a norm, whether or not those demands are made by another agent. ${ }^{31}$

If one is skeptical of the notion of being answerable to the demands of a norm rather than those of another agent, the point can be made another way. Namely, agents can make demands upon, and thus be answerable to, themselves, as in critical reflection upon the basis of one's beliefs. This is an intrapersonal relation, rather than an interpersonal one, and so remains essentially individualistic. On the other hand, the interpersonal dimension of answerability (as we will see below) is essentially interpersonal in that it concerns when and why we are accountable to the

\footnotetext{
${ }^{31}$ Nevertheless, I think it is difficult to fully dispense with the interpersonal flavor of answerability itself. This is because, when we consider whether an agent is (appropriately or rationally) answerable to some demand, we typically imagine that demand as embodied in the demands of a particular agent, not merely an impersonal norm. This is likely because we take answerability (even in the individual dimension) to be importantly connected with accountability, that is, with the notion of being accountable to the demands of other agents.
} 
actual demands of other agents, not simply the demands of some norm or those that we make upon ourselves.

\subsection{Interpersonal Answerability, Doxastic Dependence, and Social Expectations}

Being answerable for one's beliefs involves, for social creatures like us, participating in the practice of giving and exchanging reasons. Participating in this practice means that one is subject to a pro tanto obligation to respond in good faith when others ask after the reasons for one's beliefs. Call this the Demands of Interpersonal Answerability. These demands do not imply that it will always be socially or morally appropriate to demand reasons from a believer (e.g., while she is giving an important speech), but only that one is subject to a defeasible obligation. Sometimes, agents will be released from the expectation that they respond to a demand for reasons on a particular occasion, such as when a stranger demands reasons for a deeply private belief. So sometimes, social or moral norms will take precedence over the demands of answerability. What this means is not that answerability fails to apply, only that its demands are sometimes overridden by other considerations.

Additionally, beyond merely sometimes being overridden, it is also possible for a demand for reasons to be illegitimate from the outset. This can happen in at least two ways. The first is when an agent demands reasons of the wrong kind, e.g., specifically demands another's practical reasons for belief, where this is meant as a demand for justification and not merely explanation. Because belief is uniquely rationalized by epistemic or truth-related reasons, this kind of demand is illegitimate. The second way is when a demand for reasons is made in "bad faith," e.g., solely with the intention to undermine or harm another agent, such as by humiliating or unfairly discrediting her. These two kinds of demands are not merely overridden, but fail to have normative legitimacy from the start. 
But why do the Demands of Interpersonal Answerability at least sometimes have normative force upon us? One might think another version of the puzzle arises here. Namely, if we are responsible for our beliefs in the further sense of facing interpersonal justificatory demands, then surely this must be grounded in some form of doxastic control? So one might think that, even if the initial puzzle can be solved by appeal to the individual dimension of answerability, the interpersonal dimension will still require a control condition on doxastic responsibility. However, as with the initial puzzle, I want to argue that we need not appeal to doxastic control in order to vindicate the interpersonal dimension of answerability, and in particular, the idea that the Demands of Interpersonal Answerability have normative force.

Human believers are normatively subject to interpersonal answerability, I suggest, because they are participants in various social practices and institutions by which (typically mutual) relations of doxastic dependence emerge. We can characterize these relations of dependence in the following way:

Relations of Doxastic Dependence: social relations between creatures (typically agents) within which said creatures depend on one another qua believers, for both epistemic and practical resources, and are thereby vulnerable to harm.

As social animals, we depend on one another for the epistemic resources that allow for the pursuit of true belief and knowledge, which in turn make possible the effective pursuit of our practical aims and projects. As a result of this dependence, we are vulnerable to both epistemic and practical harm. We can epistemically harm others when, e.g., we provide false or misleading testimony, and thus lead them to form false beliefs. When we have false beliefs, we can also harm others practically, when the success of our social engagements turns on the truth of our beliefs. ${ }^{32}$

\footnotetext{
32 This is similar to, and arguably a version of, one of Clifford's (1877) original arguments for an "ethics of belief" in his seminal essay of that title. Clifford argues that there is an ethical norm of responsible belief because when we believe irresponsibly, we not only risk poisoning the well of shared knowledge and evidence, but we also risk doing serious and sometimes irreversible practical harm to others.
} 
We can imagine various kinds of relations of doxastic dependence, from the rather mundane - asking a stranger on the street for the time or for directions - to the deep and finegrained-like the relation between a teacher and student, or between two people in a close, committed relationship. We can imagine relations of doxastic dependence that are unidirectionalwe collectively depend on weather forecasters, but they do not thereby depend on us-or bidirectional/mutual — such as virtually any group collectively engaged in a project, such as researchers in a lab, or members of a legal team.

Because we depend on one another for both epistemic and practical resources, and thereby risk harm, we engage in practices of giving and exchanging reasons, such as that of answerability, by which we hold each other accountable to being (minimally) good epistemic-social agents. Belief motivates and underlies both non-linguistic action and assertion (e.g., testimony), and so we expect one another to act on and assert only those beliefs that we have good reason to think are true. And this extends, I think, to the expectation that we and others will only hold beliefs that we or they have good reason to think are true. This is because we are answerable not only for our actions but, more fundamentally, for the beliefs that underlie them. This is why answerability is first and foremost a doxastic or attitudinal matter.

The normativity of the interpersonal dimension of answerability, then, is bound up with social practices and shared expectations that we will avoid harming one another when engaged in relations of doxastic dependence. However, these need not be expectations of particular agents; they can also be general expectations associated with being a member of the relevant practice(s). Social practices are typically partly defined by such general expectations about how one will engage in the practice. ${ }^{33}$ Answerability is one of the mechanisms by which we hold one another to

\footnotetext{
${ }^{33}$ See Goldberg (2018) for a helpful and well-developed account of the relation between (general) social expectations and epistemic normativity. Goldberg is mostly concerned with epistemic justification rather than responsibility, but his account of expectations, social practices, and the conditions for the normative legitimacy of both is instructive.
} 
these expectations. And expectations, when legitimate, are not merely evaluative, but rather normative in that they reflect facts or claims about what one ought to do. We might regard the relevant expectations as legitimate since they centrally involve norms of harm-avoidance: we legitimately expect others (in the normative sense of 'expect') to satisfy the demands associated with interpersonal answerability because this is how we hold one another accountable to avoiding harm, by, e.g., being reliable informants, etc.

One might object that this explanation of the normativity involved in interpersonal answerability can only work for beliefs that in fact play a role in relations of doxastic dependence, e.g., beliefs that we in fact testify to others on the basis of. But this would fail to account for many of our beliefs that do not play such a role, so my account would have only rather limited applicability, and would imply that we are in fact not responsible for many of our beliefs. But this isn't right, for three reasons. First, while we can't always know ahead of time which beliefs will play a role in relations of dependence, any belief could in principle play a role in, e.g., providing others with reliable testimony. Second, whether or not we in fact testify upon a particular belief, false and unjustified beliefs play a role in interpersonal interaction and cooperative endeavors, whereby they can lead to harm to those with whom we are cooperating. Similarly, the intellectual habits associated with forming and holding beliefs for (in)sufficient reason are connected with our general reliability as social informants and cooperators. Finally, if we take the "web of belief" metaphor or some kind of belief-set-holism seriously, then it is hard to see how we are to separate various subsets of an agent's beliefs from the whole set, and regard only certain subsets as relevant to her role and capacity as a social agent.

However, it's true that fulfilling the demands of interpersonal answerability won't by itself ensure the avoidance of harm. Someone can still cause harm despite having adequately responded to various demands for reasons. But answerability can play a role in social practices of epistemic 
policing that will make harm less likely by making various forms of epistemic irresponsibility less common, or at least by identifying those who engage in epistemically irresponsible behavior. ${ }^{34}$ This, at least, is the hope. But answerability need not always be successful on its own in preventing harm in order to embody normative demands or obligations. The fact that it plays a central role in social practices aimed at preventing harm seems enough.

It's important to note, though, that the social normativity here can't arise merely from the fact that we typically do engage in relations of doxastic dependence, since this would be to infer an 'ought' from an 'is'. Rather, it is that, as a general rule, we must depend on one another in the ways discussed above in order to do well, epistemically and practically. As social creatures, we must depend on one another to succeed as individual practical and epistemic agents. Both in seeking the truth and in seeking the good, we generally must do so with others. So our shared expectations regarding one another as epistemic agents and responsible believers are given force by the fact that our best chance at epistemic and practical flourishing makes sociality and relations of dependence effectively non-optional.

However, one might object that, since I've argued that the normative force of interpersonal answerability depends on social relations and shared expectations, my approach cannot account for, e.g., hermits and people on desert islands. That is, if an agent is not engaged in social relations of dependence, or part of a human community, it is hard to see why she would be responsible for her beliefs beyond merely the individual dimension of answerability.

It is true that the hermit might not know, or might not care, what others expect of her qua believer. However, my account does not require that agents are always or consistently engaged in active, particular social relations or interactions in order to be subject to interpersonal

\footnotetext{
${ }^{34}$ See Chrisman (2008) for a discussion of a similar idea in context of epistemic normativity and the doxastic 'ought'.
} 
answerability. The fact that a hermit could enter into social relations by which other agents would rely on her for information and expect her to, e.g., avoid deceiving or misleading them, is enough to make her subject to the demands of interpersonal answerability. The hermit could still be reasonably expected to help a group of shipwrecked people survive after they wash up on the island, and part of this is being answerable for her beliefs about where to find food, dangerous wildlife, etc. It is true that she would not be subject to any particular interpersonal demands before she entered into such exchanges. But this is the difference between being subject to a particular demand for reasons at a particular time and being subject to a general expectation associated with participation in a practice.

Notice that what I've said about the hermit is, in an important sense, not different in principle from what we might say about the average, socially engaged agent. Even the average social agent is not always engaged in social interactions or relations of doxastic dependence. But if an agent takes a solitary trip to a place with no one else around, and is fully out of contact, we don't think she is thereby no longer responsible for her beliefs, even in the interpersonal sense. Why is this? I think it is because the sense in which we are social creatures, and the associated sense in which we are engaged in a kind of collective project, extends beyond our current circumstances at any given time. We do not leave the practice associated with interpersonal answerability simply by temporarily ceasing to actively engage in relations of doxastic dependence. We will, or at least should, continue to feel the normative force of the practice even when we are not actively engaged in it. ${ }^{35}$ Arguably, we do not even leave the practice by deciding to live as hermits: we still continue to live in a world populated by other agents who can make legitimate demands upon us. ${ }^{36}$

\footnotetext{
${ }^{35}$ This is effectively what Reed (2018) calls the normative persistence of social practices.

${ }^{36}$ The sense in which we can make legitimate demands upon one another merely in virtue of our common sociality or our shared humanity is likely connected with the most fundamental moral norms or values that bind us together,
} 
However, one might have a similar kind of worry about (cultural) relativism. For imagine that there is a society that has no interest in, and no practices involving, exchanging reasons for belief. We would also have to imagine that there is no general social expectation within this society that others will try to justify their beliefs to those that depend on them as believers. If such a society is possible, it might appear that the interpersonal dimension of answerability as I have described it would not apply to its members. However, even in such a society, two things would still likely be true. First, its members would still enter into relations of doxastic dependence and would still be subject to the individual dimension of answerability, and so at least the groundwork for the interpersonal dimension, so to speak, would be there. And second, we presumably must imagine that this society could enter into social commerce with other communities that do engage in practices of exchanging reasons, justifying beliefs, etc., and so, like the hermit above, would be subject to the expectations of their new interlocutors. Of course, one might object that we could imagine a society like the one above - no practices of exchanging reasons, etc. - that is, e.g., totally alone in the universe. In such a case, the most plausible thing to say is simply to admit that its members would not be subject to the interpersonal dimension of answerability. However, such a case is so far removed from the features of actual human sociality that I have tried to capture here that I am not especially worried if my account fails to apply.

\section{Hieronymi on Answerability and Responsibility for Belief}

I now want to return to Pamela Hieronymi's (2008) account of doxastic responsibility, in order to further clarify how my view relates to and is meant to go beyond hers. Hieronymi gives an account of responsibility for belief that begins with the notion of answerability. She says:

[I start] with a very minimal notion, which I call answerability. It seems plausible that we

such as, e.g., the moral obligation to respect the intrinsic rational dignity of others. Consideration of the relation between epistemic normativity and fundamental moral normativity is something I hope to return to elsewhere. 
are responsible for our beliefs in at least the minimal sense that we can be asked for our reasons for believing (which is not to say that we must have reasons for each of our beliefs). This minimal notion is then shown to be continuous with a more robust notion of responsibility. ${ }^{37}$

Hieronymi suggests that answerability follows simply from the nature of belief, namely, the fact that belief is a "commitment-constituted attitude": to hold a belief is to express some of one's evaluative commitments. However, she also argues that we are responsible for our beliefs because we exercise "evaluative control" over them, which we do by evaluating the truth of their content and deciding whether they serve as the satisfactory answer to a question. So Hieronymi sees doxastic responsibility as partially grounded in our ability to (non-voluntarily) control our beliefs through something like doxastic deliberation (though, importantly, not through 'reflection').

The fundamental idea for Hieronymi, though, is the sense in which our commitmentconstituted attitudes, such as our beliefs, "constitute one's moral [or epistemic] personality.",38 Hieronymi suggests that answerability is only a minimal form of responsibility that is continuous with a more robust form of responsibility, which ends up being moral responsibility proper. Doxastic responsibility is ultimately to be understood as responsibility for one's beliefs insofar as those attitudes play a constitutive role in one's moral (or epistemic) personality. Hieronymi's ultimate suggestion is that epistemic responsibility is structurally analogous to moral responsibility—where they both are fundamentally responsibility for one's "rational self"—but that the standards of assessment embodied in the reactive attitudes are simply different for each, i.e., epistemic versus moral.

As I understand Hieronymi here, she is effectively giving an account of what I have called the individual dimension of answerability, which she then connects with a notion of accountability in terms of the reactive attitudes. Hieronymi's strategy is structurally similar to my own in the

\footnotetext{
${ }^{37}$ Hieronymi (2008: 358).

${ }^{38}$ Hieronymi (2008: 372).
} 
following way: she suggests that while a form of answerability follows from the nature of belief, it must be connected up with a more robust form of responsibility. I have suggested something similar. But where Hieronymi explains the normative force of doxastic responsibility in terms of one's "epistemic personality" being the proper target of the reactive attitudes, I have sought to explain the normative force in terms of our social dependence on one another qua believers. In this sense, while the structure of my account is not unlike Hieronymi's, it is precisely my account of the interpersonal dimension of answerability that is supposed to diverge from and go beyond hers.

Nevertheless, it may be that answerability needs to be connected up with a more normatively robust form of responsibility in both the individual and the interpersonal dimensions. If so, then something like Hieronymi's account might be required in making sense of the individual dimension of answerability. However, I argued above that accounts of the individual dimension on its own seem unable to answer important questions about how and why being responsible for our beliefs has various social features and involves being responsible to others. If I am right about this, and I am correct in interpreting Hieronymi as giving an account only of the individual dimension, then even if we were to adopt her account, it would still need to be supplemented with an account of the interpersonal dimension of answerability. So, it is primarily the need for an account of the interpersonal dimension, and the associated social features of doxastic responsibility, that I have tried to motivate here.

\section{Objections and Replies}

\subsection{Objection 1: Responsibility for Action, Not Belief}

I'd now like to address three salient objections to the account I've offered. The first objection one might have is that what we are really holding each other responsible for with respect to interpersonal answerability are our actions, not our beliefs. This is because, the objection goes, 
we harm others with our actions, not our beliefs, and the normative force of answerability is supposed to be based on practices of epistemic accountability and expectations of harm-avoidance. So even though our beliefs may underlie and motivate our actions, it is still our actions that are the loci of responsibility. Thus, the objection goes, my account fails as an account of doxastic responsibility beyond merely the individual dimension of answerability.

I think this objection fails for two reasons. The first is that it conflates the proximal cause of harm (our actions) with the sole locus of responsibility. The fact that our actions may be at the end of the causal chain that results in some harm does not mean that we cannot be responsible for other parts of that chain. Indeed, given that our beliefs typically motivate and underlie our actions, there is reason to think that doxastic responsibility is more fundamental than practical responsibility. And so, if we are to hold one another responsible for our actions, we must also, and likely initially, hold one another responsible for our beliefs. This is because beliefs play an essential role in both justifying and excusing actions: e.g., a justified or rational belief can excuse an otherwise blameworthy action. So even if it is true that our actions are the most immediate causes of harm, this does not mean that we are not also responsible for the doxastic attitudes that underlie those actions.

Second, it is important to note that part of the content of the objection itself-that only actions can harm - has recently become controversial. Some have recently argued that we can harm or wrong others with our beliefs - e.g., what Rima Basu and Mark Schroeder (2019) call doxastic wronging. ${ }^{39}$ And so there may be reason to doubt the force of the objection right out of the gate.

${ }^{39}$ For example, see Basu (2018, Forthcoming), Basu \& Schroeder (2019), and Marušić \& White (2018). 


\subsection{Objection 2: Peels' Objection - No Blame, No Responsibility}

Rik Peels (2017) has recently offered a series of objections to 'no control required' views of doxastic responsibility (and doxastic obligations). He offers separate objections to four different versions of this approach, ${ }^{40}$ but the general thrust of them is this: it is hard to see how we can hold someone responsible for something (in this case, a belief) if there is nothing they can do to (voluntarily) change it. Responsibility, Peels holds, implies that blame is or might be appropriate. But blame implies that the subject of responsibility could have (reasonably been expected to have) done better than she did. But if this is so, then she must have had some control, or at least influence, over whether or not she in fact did better. Thus, Peels concludes, 'no control' views might be giving an account of some form of doxastic normativity, but they are not accounts of responsibility, since they cannot justify attributions of blame.

Understanding doxastic responsibility in terms of answerability gives us a way of seeing how and why blame and responsibility might come apart. In particular, one might be excused from blame (or praise), but not from doxastic responsibility (i.e., answerability) itself..$^{41}$ As Smith (2015b: 116) argues, “concerns about 'fairness' [of, e.g., blame] can be accommodated at the level of excuse and justification: being 'answerable for' something does not automatically mean that one is liable for any particular kind of blame for it." We might, for instance, excuse someone from blame because of non-culpable ignorance, but still hold her answerable for her belief(s), demand her reasons, and offer rational criticism of her reasoning. ${ }^{42}$

Hieronymi makes a related but unique point: understanding what it is to be responsible for something simply in terms of being deserving of certain consequences (e.g., forms of blame) on

\footnotetext{
${ }^{40}$ Namely, Chuard \& Southwood (2009), Chrisman (2008), Feldman (2000, 2008), and Kornblith (1983, 2001). Though, again, this is a tricky issue, because none of these theorists are explicitly giving accounts of doxastic or epistemic responsibility. So there is a sense in which Peels' criticism perhaps partly misses the mark.

${ }^{41}$ Again, see Fricker (2016) on the notion of "no-fault epistemic responsibility", which is relevant here. See also Smith (2015b) for an analogous argument regarding moral responsibility and blame.

${ }^{42}$ See Westlund (2018) for a relevant discussion of answerability without blame.
} 
account of that thing obscures the fact that holding someone responsible for something and having certain reactions or responses to their norm-violation are justified in importantly different ways. Holding an agent responsible for a belief can be justified simply because it makes sense to ask her for her reasons in support of it. But, Hieronymi notes, many attitudes or responses to normviolation (she speaks specifically of moral failing) like blame are justified only in terms of specific kinds of reasons, e.g., some are sensitive to considerations of fairness and some are not. And so the justification conditions for 'holding responsible' and 'having such-and-such response to normviolation' are importantly distinct. ${ }^{43}$

So, the idea then is that we can distinguish between the basic conditions on doxastic responsibility, on the one hand, and conditions on the propriety of various critical responses (like blame), on the other. If one can satisfy the conditions on 'being responsible for' a belief without necessarily satisfying conditions on being blameworthy (or praiseworthy) for that belief, then Peels' objection can be defused. One can give an account of the conditions on doxastic responsibility without thereby having to give an account of the conditions on doxastic blame. ${ }^{44}$

\subsection{Objection 3: Answerability Mistakes Rational Evaluability for Responsibility}

Lastly, one might wonder how being answerable for a belief goes beyond the idea that one's belief can be measured against an evaluative standard. For example, McHugh (2013) objects that answerability views fail to capture the accountability-dimension of responsibility, since they involve mere rational evaluability. But, his objection goes, responsibility is more than mere rational evaluability: it is accountability to norms or expectations.

\footnotetext{
${ }^{43}$ See Hieronymi, "I'll Bet You Think This Blame is About You" (unpublished/in-progress manuscript).

${ }^{44}$ It is worth noting that there is a deep, substantive disagreement at issue here: roughly, the disagreement between Strawsonians (like Peels) and Scanlonians (like Smith, myself, and perhaps also Hieronymi). This is a disagreement about whether characterizing the basic conditions on (moral or epistemic) responsibility constitutively involves giving conditions on blame and praise. Strawsonians say 'yes' and Scanlonians say 'no'. It is beyond the scope of this paper to weigh in on this disagreement to any greater degree. But it is important to note that Peels' objection hangs on this dispute about the basic structure of responsibility.
} 
Answerability is typically not intended to embody mere rational evaluability. Rather, being called upon to justify one's actions and attitudes is often just part of what it is to be accountable to norms or expectations. So accountability and answerability are often importantly linked: to be called to answer for something is to be held to account. Nevertheless, answerability theorists also typically hold that whether one is accountable to any given norm, and whether one is eligible for, e.g., blame for violating that norm, is separate from the more fundamental issue of whether one is responsible for one's attitude. For example, Angela Smith says the following on this issue:

We need only make clear that when an agent is 'held to account' for something that involves the violation of a duty to others, she is eligible for forms of moral [or rational] response that would not be appropriate in cases where she is 'held to account' for something that does not involve a violation of what we owe to others. But this difference at the level of moral [or rational] response is, in my view, much less important than the unity at the level of basic responsibility: In both sorts of cases, we are regarding her as 'answerable for' the thing in question in virtue of the fact that it reflects her assessment of reasons, and we are 'holding her to account' in the appropriate way for it. ${ }^{45}$

Smith is here talking about moral responsibility. But the lesson can be applied analogously to doxastic responsibility. The fact that answerability is supposed, in principle, to be separate from questions about accountability to specific norms or expectations does not mean that answerability is mere rational evaluability. It just means that the basic condition of 'being responsible for' an attitude is not understood in relation to being accountable to any particular norms or expectations bearing on that attitude.

If the issue here is reframed in terms of what gives the demands of answerability normative force, beyond mere evaluative power, I have argued that it is our relations of doxastic dependence and social expectations that do so. We are not subject merely to various evaluative standards against which our beliefs might be measured, but also to expectations associated with our social

\footnotetext{
${ }^{45}$ Smith (2015b, 113).
} 
relations of dependence. I have suggested that one of the central expectations associated with these relations is that we will make good faith efforts to participate in the practice of giving and exchanging reasons. In this sense, the interpersonal dimension of answerability is connected to a form of accountability: it is not only to be answerable for one's beliefs in the basic sense associated with the individual dimension, but also to be answerable to the expectations and demands of others within practices and relations of dependence.

\section{Conclusion}

Let's return to the puzzle which has framed this paper:

(RESPONSIBLE) We sometimes rightly hold agents responsible for their doxastic attitudes. (CONTROL) Voluntary control over $\mathrm{X}$ is a prerequisite for responsibility for $\mathrm{X}$.

(NON-VOLUNTARY) Beliefs are not subject to the will, that is, we lack voluntary control over them.

I've argued that versions of this puzzle arise with respect to two different dimensions of doxastic responsibility understood as answerability: the individual and the interpersonal dimensions. I've suggested that even if we can resolve the puzzle associated with the individual dimension, we also need an account of the interpersonal dimension, which involves an account of the social features of doxastic responsibility. As deeply social creatures, we depend on one another qua believers as an unavoidable part of the collective project of pursuing epistemic and practical success. As a result, we depend on one another in ways that make us vulnerable to both epistemic and moral harm. It is because of these relations of dependence and vulnerability that the demands of interpersonal answerability normative force upon us: we are subject to legitimate expectations associated with participating in relations and practices of dependence.

One of the central contentions of this paper has been that we can articulate an account of doxastic responsibility without depending on the notion of doxastic control. The other central 
contention has been that responsibility for belief involves responsibility to others: a complete account of doxastic responsibility must go beyond merely the individual dimension of that responsibility. But these two central points are also importantly connected: it was my hope that a greater appreciation of and focus on the social features of doxastic responsibility, within the interpersonal dimension, would help to motivate the claim that we can reject (CONTROL). The idea has been that we depend on one another qua believers, and so are answerable to one another for our beliefs in the interpersonal sense, and that this is independent of the issue of if and when we can exercise control over our beliefs. And so, in effect, my suggestion is that the central explanatory and normative role often played by doxastic control in accounts of responsibility for belief can be filled by the social features of this responsibility. Thus, the account I have offered here depends on adopting and taking seriously a thoroughly social perspective on our epistemic and doxastic lives. 


\section{Works Cited}

Alston, William. (1988) "The Deontological Conception of Epistemic Justification.”

Philosophical Perspectives, 2: 257-299.

Basu, Rima. (2018) “Can Beliefs Wrong?” Philosophical Topics 46(1):1-17.

Basu, Rima. (forthcoming) "The Wrongs of Racist Beliefs," Philosophical Studies: 1-19.

Basu, Rima \& Schroeder, Mark. (2019) "Doxastic Wrongings," in Pragmatic Encroachment in

Epistemology, eds. Brian Kim and Matthew McGrath. Routledge: 181-205.

Boyle, Matthew. (2009) "Active Belief." Canadian Journal of Philosophy. 39(1): 119-147.

Boyle, Matthew. (2011) “'Making up Your Mind' and the Activity of Reason.” Philosophers'

Imprint, 11(17).

Calhoun, Cheshire. (1989) "Responsibility \& Reproach." Ethics, 99: 389-406.

Chrisman, Matthew. (2008) "Ought to Believe." The Journal of Philosophy.

Chrisman, Matthew. (2018) "Epistemic Normativity and Cognitive Agency." Noûs, 52(3): 508-529.

Clifford, William K. (1877) “The Ethics of Belief.” Contemporary Review.

Fischer, John M. \& Ravizza, Mark. (1998) Responsibility and Control: A Theory of Moral Responsibility. Cambridge University Press.

Fricker, Miranda. (2016) "Fault and No-Fault Responsibility for Implicit Prejudice: A Space for Epistemic 'Agent-Regret'." In The Epistemic Life of Groups: Essays in the Epistemology of Collectives. Eds. Michael S. Brady and Miranda Fricker. OUP.

Goldberg, Sanford C. (2017) "Should Have Known.” Synthese, 194(8): 2863-2894.

Goldberg, Sanford C. (2018) To the Best of Our Knowledge: Social Expectations and Epistemic Normativity. Oxford University Press.

Heller, Mark. (2000) "Hobartian Voluntarism: Grounding a Deontological Conception of

Epistemic Justification." Pacific Philosophical Quarterly 81: 130-141.

Hieronymi, Pamela. (2005) “The Wrong Kind of Reason.” The Journal of Philosophy, 102(9): 437-457.

Hieronymi, Pamela. (2006) “Controlling Attitudes.” Pacific Philosophical Quarterly 87: 45-74.

Hieronymi, Pamela. (2008) "Responsibility for Believing." Synthese 161: 357-373.

Levy, Neil. (2007) "Doxastic Responsibility." Synthese.

Marušić, Berislav \& White, Stephen. (2018) "How Can Beliefs Wrong? A Strawsonian

Epistemology." Philosophical Topics, 46(1): 97-114.

McCormick, Miriam S. (2018) "Responding to Skepticism About Doxastic Agency." Erkenntnis, 83: 627-645.

McCormick, Miriam S. (2015) Believing Against the Evidence: Agency and the Ethics of Belief. Routledge.

McCormick, Miriam S. (2011) “Taking Control of Belief." Philosophical Explorations, 14(2): 169-183.

McHugh, Conor. (2017) “Attitudinal Control.” Synthese, 194(8): 2745-2762.

McHugh, Conor. (2014) "Exercising Doxastic Freedom." Philosophy and Phenomenological Research: 1-37. 
McHugh, Conor. (2013) "Epistemic Responsibility and Doxastic Agency.” Philosophical Issues, Epistemic Agency (23): 132-157.

McHugh, Conor. (2011) "What Do We Aim at When We Believe?" Dialectica, 65(3): 369-392.

McHugh, Conor \& Whiting, Daniel. (2014) “The Normativity of Belief.” Analysis, 74(4): 698-713.

Moran, Richard. (2001) Authority and Estrangement. Princeton University Press.

Nolfi, Kate. (2015) "How to be a Normativist about the Nature of Belief." Pacific Philosophical Quarterly, 96(2): 181-204.

Osborne, Robert. (2019) "Doxastic Responsibility, Guidance Control, and Ownership of Belief." Episteme.

Peels, Rik. (2017) Responsible Belief. New York: Oxford University Press.

Reed, Baron. (2018) "Practical Interests and Reasons for Belief." In Normativity: Epistemic and Practical. OUP.

Ryan, Sharon. (2003) "Doxastic Compatibilism and the Ethics of Belief." Philosophical Studies, 114: 47-79.

Shoemaker, David. (2011) “Attributability, Answerability, and Accountability: Toward a Wider Theory of Moral Responsibility." Ethics 121, 3: 603-32.

Smith, Angela M. (2015a) “Attitudes, Tracing, and Control.” Journal of Applied Philosophy, 32(2): 115-132.

Smith, Angela M. (2015b) "Responsibility as Answerability." Inquiry, 58(2).

Smith, Angela M. (2012) "Attributability, Answerability, and Accountability: In Defense of a Unified Account." Ethics, 122(3): 575-589.

Smith, Angela M. (2008) “Control, Responsibility, and Moral Assessment.” Philosophical Studies, 138(3).

Smith, Angela M. (2005) "Responsibility for Attitudes: Activity and Passivity in Mental Life." Ethics, 115(2).

Steup, Matthias. (2000) "Doxastic Voluntarism and Epistemic Deontology.” Acta Analytica 15(1): 25-56.

Strawson, Peter F. (1962) "Freedom and Resentment." Proceedings of the Aristotelian Society.

Tollefsen, Deborah. (2017) "Epistemic Reactive Attitudes.” American Philosophical Quarterly.

Wallace, R. Jay. (1994) Responsibility and the Moral Sentiments. Harvard University Press.

Watson, Gary. (1996) “Two Faces of Responsibility.” Philosophical Topics, 24(2): 227-248.

Weatherson, Brian. (2008) “Deontology and Descartes' Demon." The Journal of Philosophy.

Wedgwood, Ralph. (2002) “The Aim of Belief,” Philosophical Perspectives 16: 267-297.

Whiting, Daniel. (2012) “Does Belief (Only) Aim at Truth?” Pacific Philosophical Quarterly, 93(2): 279-300.

Williams, Bernard. (1973) Problems of the Self. Cambridge: Cambridge University Press.

Westlund, Andrea C. (2018) “Answerability without Blame?” In Social Dimensions of Moral Responsibility. Edited by Katrina Hutchison, Catriona Mackenzie, and Marina Oshana. OUP: 253-274. 